\title{
Awareness about Tobacco Habit, Its Hazards and Willingness to Quit the Habit among Patients.
}

\author{
Dr. Sushil B. Naik ${ }^{1}$, Dr. Swapnil N. Patil ${ }^{2}$, Dr. Seema D. Kamble ${ }^{3}$, \\ Dr. Mohammed Atif Khan ${ }^{4}$. \\ ${ }^{1,3,4}$ (Department of Public Health Dentistry, VSPM'S Dental College and Research Centre,Nagpur.MUHS \\ Nashik. India.) \\ ${ }^{2}$ (Department of Conservative Dentistry, VSPM'S Dental College and Research Centre,Nagpur.MUHS Nashik. \\ India.)
}

\begin{abstract}
Tobacco use is one of the leading preventable causes of premature death, disease and disability around the world. An estimated 4.9 million deaths occurring annually can be attributed to tobacco use. This study was carried out to assess awareness of patients about tobacco habit and their willingness to quit the habit. A cross sectional study was conducted amongst the patients. The sample size was decided based on prevalence rate of awareness in previous studies. The study comprised of 200 subjects. Pre-set pre-tested questionnaire was used for interview purpose; the patients were given a questionnaire consisting of 13 questions regarding Personal information, education, duration \& frequency of their tobacco habits, its hazards and their willingness to quit the habit. There is an urgent need to take effective steps, especially on launching community awareness programs for the school children and public to educate them about the consequences of tobacco use, and on counselling of patients for de-addiction of this habit.
\end{abstract}

Keywords - awareness, de-addiction, hazards, quit, tobacco.

\section{INTRODUCTION}

Human beings have been using tobacco since 600 A.D. Columbus who came to know about it from the Caribbeans during his historical journeys introduced it in Europe. The Portuguese introduced it in India. Harmful effects of tobacco have been recognized over the last 1000 years. Historically, three contemporary rulers, King James I of England, Shah Abbas of Persia and the Mughal emperor Jahangir of India in 16th century had noticed the harmful effects of tobacco and tried to ban it ${ }^{[1]}$. Tobacco use is one of the leading preventable causes of premature death, disease and disability around the world. An estimated 4.9 million deaths occurring annually can be attributed to tobacco use. This figure is expected to rise to about 10 million by the year 2020, if the current epidemic continues and more than $70 \%$ of these deaths are expected to occur in developing countries. ${ }^{[2]}$

Globally, cigarette smoking is the dominant form of tobacco use. In the Indian context, tobacco use implies a varied range of chewing and smoking forms of tobacco available at different price points, reflecting the varying socio-economic and demographic patterns of consumption. Tobacco is consumed in a variety of, both smoking and smokeless forms, e.g. bidi, gutkha, khaini, paan masala, hookah, cigarettes, cigars, chillum, chutta, gul, mawa, misri, etc. Tobacco is also a part of the socio-cultural milieu in various societies, especially in the Eastern, Northern, and Northeastern parts of the country. India is the second largest consumer of tobacco products and third largest producer of tobacco in the world. In order to facilitate the implementation of the tobacco control laws, bring about greater awareness regarding harmful effects of tobacco and fulfill obligation(s) under the WHO Framework Convention on Tobacco Control (WHO FCTC), the Government of India launched the National Tobacco Control Programme (NTCP) in the country. ${ }^{[3]}$

Several strategies have been shown to reduce tobacco use. However, more than 50 years after the health dangers of smoking were scientifically proven, and more than 20 years after evidence confirmed the hazards of second-hand smoke, few countries have implemented effective and recognized strategies to control the tobacco epidemic. International efforts led by WHO resulted in rapid entry into force of the WHO Framework Convention on Tobacco Control (WHO FCTC), which has 168 signatories and more than 150 Parties. Achievement of tobacco control goals will require coordination among many government agencies, academic institutions, professional associations and civil society organizations at the country level, as well as the coordinated support of international cooperation and development agencies.

As per India's Cigarette and Other Tobacco Product Act 2003 (COTPA), selling tobacco to minors or selling of tobacco by minors (under the age of 18) is legally forbidden and violation of the same is a punishable 
offence. Same applies to selling of tobacco containing items within 100 yards radius of any educational premises ${ }^{[6]}$.

This study was carried out to assess awareness of patients about tobacco habit and their willingness to quit the habit.

\section{SUBJECTS AND METHODS}

A cross sectional study was conducted amongst the patients referred to Department. of Public Health Dentistry for counseling, the sample size was decided based on prevalence rate of awareness in previous studies. Simple random sampling method was used for collection of data. The approval was obtained from the institutional ethics committee where the study was carried out. The study comprised of 200 subjects, the patients. There were 160 males and 40 females.

Pre-set pre-tested questionnaire was used for interview purpose; the patients were given a questionnaire consisting of 13 questions regarding Personal information, education, duration \& frequency of their tobacco habits, its hazards and their willingness to quit the habit. The statistical analysis was done on proportional percentage basis, study variables being tobacco-chewing smoking, quitting attempts, quitting reasons, knowledge regarding health hazards, age of initiation of habit.

\section{RESULTS}

In the present study, total 200 patients who visited Department of Public Health Dentistry, oral oncology unit and de-addiction centre, VSPM Dental College and R.C. Nagpur, were included. There were 160 $(80 \%)$ males and 40 females (20\%). (Table 1, Fig 1)

72 (36\%) patients were involved in use of smokeless form, 51 (25.5\%) patients were involved in use of smoking form and 77 (38.5\%) patients were having habit of smokeless as well as smoked form of tobacco. Among the smokers, females were only $1 \%$. (Table .1 Fig 2).

Among these patients, the prevalence of habit was $28.5 \%$ up to the age of 25 years and the habit was maximum $53 \%$ in the age group of 26-50 years. Minimum age of initiation of tobacco habit was 10 years in males and 13 years in females. (Table.2, Fig 3).

Among these patients, $71.5 \%$ patients had knowledge of hazards of tobacco habit but only $46 \%$ patients had tried to quit the habit however when questioned about their willingness to quit $73.5 \%$ patients were willing to quit. (Table.5, 6, Fig.5,6).

Among those patients who were willing to quit the habit 147 (73.5), when asked about source of motivation $96(65.3 \%)$ were motivated Doctors, $20(13.6 \%)$ by family and $31(21 \%)$ by television. (Table.7, Fig 7). $58 \%$ patients admitted that the government should ban the tobacco use in India. (Table.8, Fig 8).

\section{FIGURES AND TABLES}

\begin{tabular}{|l|ll|ll|ll|}
\hline \multirow{2}{*}{ Tobacco habit } & \multicolumn{2}{|l|}{ Male } & Female & Total \\
\cline { 2 - 7 } & No. $(\%)$ & No. $(\%)$ & No. & $(\%)$ \\
\hline Smokeless & 41 & $(20.5)$ & 31 & $(15.5)$ & 72 & $(36)$ \\
\hline Smoking & 49 & $(24.5)$ & 02 & $(1)$ & 51 & $(25.5)$ \\
\hline Both & 69 & $(34.5)$ & 08 & $(4)$ & 77 & $(38.5)$ \\
\hline Total & 160 & $(80)$ & 40 & $(20)$ & 200 & $(100)$ \\
\hline
\end{tabular}

Table-1: Distribution of study participants according to tobacco habit and gender.

\begin{tabular}{|l|ll|ll|ll|l|l|}
\hline \multirow{2}{*}{ Gender } & \multicolumn{2}{|l|}{$1-25 \mathrm{yrs}$} & \multicolumn{2}{|l|}{$26-50$ yrs } & \multicolumn{2}{l|}{51 above } & \multicolumn{2}{l|}{ Total } \\
\cline { 2 - 10 } & No & $(\%)$ & No & $(\%)$ & No & $(\%)$ & No & $(\%)$ \\
\hline Male & 53 & $(26.5)$ & 78 & $(39)$ & 29 & $(14.5)$ & 160 & $(80)$ \\
\hline Female & 04 & $(2)$ & 28 & $(14)$ & 08 & $(4)$ & 40 & $(20)$ \\
\hline Total & 57 & $(28.5)$ & 106 & $(53)$ & 37 & $(18.5)$ & 200 & $(100)$ \\
\hline
\end{tabular}

Table-2: Distribution of study participants according to age group

\begin{tabular}{|l|l|l|}
\hline & Male & Female \\
\hline Minimum age of initiation of habit in years & 10 & 13 \\
\hline
\end{tabular}

Table-3: Minimum age of initiation of habit in study participants.

\begin{tabular}{|c|c|c|c|}
\hline & Male & Female & Total \\
\hline & No $(\%)$ & No $(\%)$ & No $(\%)$ \\
\hline $\begin{array}{l}\text { Know the habit is } \\
\text { hazardous }\end{array}$ & $114 \quad$ (57) & $29 \quad(14.5)$ & $143 \quad(71.5)$ \\
\hline
\end{tabular}

Table-4: Distribution of study participants according to knowledge about tobacco hazard 
Awareness About Tobacco Habit, Its Hazards And Willingness To Quit The Habit Among Patients.

\begin{tabular}{|l|ll|ll|}
\hline \multirow{2}{*}{ Gender } & \multicolumn{3}{|l|}{ Willing to quit } & \multicolumn{2}{l|}{ Not willing to quit } \\
\cline { 2 - 5 } & No. & $\%$ & No. & $\%$ \\
\hline Male & 114 & $(57)$ & 46 & $(23)$ \\
\hline Female & 33 & $(16.5)$ & 7 & $(3.5)$ \\
\hline Total & 147 & $(73.5)$ & 53 & $(26.5)$ \\
\hline
\end{tabular}

Table-5: Distribution of study participants according to willingness to quit the tobacco habit.

\begin{tabular}{|l|ll|lc|}
\hline \multirow{2}{*}{ Gender } & \multicolumn{3}{|l|}{ Tried to quit } & \multicolumn{2}{l|}{ Not tried } \\
\cline { 2 - 5 } & No. $\%$ & No. & $\%$ \\
\hline Male & 78 & $(39)$ & 82 & $(41)$ \\
\hline Female & 14 & $(7)$ & 26 & $(13)$ \\
\hline Total & 92 & $(46)$ & 108 & $(54)$ \\
\hline
\end{tabular}

Table-6: Distribution of study participants according to efforts to quit the tobacco habit.

\begin{tabular}{|l|ll|}
\hline Source of motivation & No. & $\%$ \\
\hline Doctors & 96 & $(65.3)$ \\
\hline Family & 20 & $(13.6)$ \\
\hline Telivision & 31 & $(21.0)$ \\
\hline Total & 147 & \\
\hline
\end{tabular}

Table-7: Distribution of study participants according to source of motivation to quit habit

\begin{tabular}{|l|ll|ll|}
\hline \multirow{2}{*}{ Gender } & \multicolumn{2}{|l|}{ Govt. should ban } & \multicolumn{2}{l|}{ Govt. should not ban } \\
\cline { 2 - 5 } & No & $(\%)$ & No & $(\%)$ \\
\hline Male & 97 & $(48.5)$ & 62 & $(31)$ \\
\hline Female & 19 & $(9.5)$ & 22 & $(11)$ \\
\hline Total & 116 & $(58)$ & 84 & $(42)$ \\
\hline
\end{tabular}

Table-8: Distribution of study participants according to their opinion about Govt. ban on tobacco.

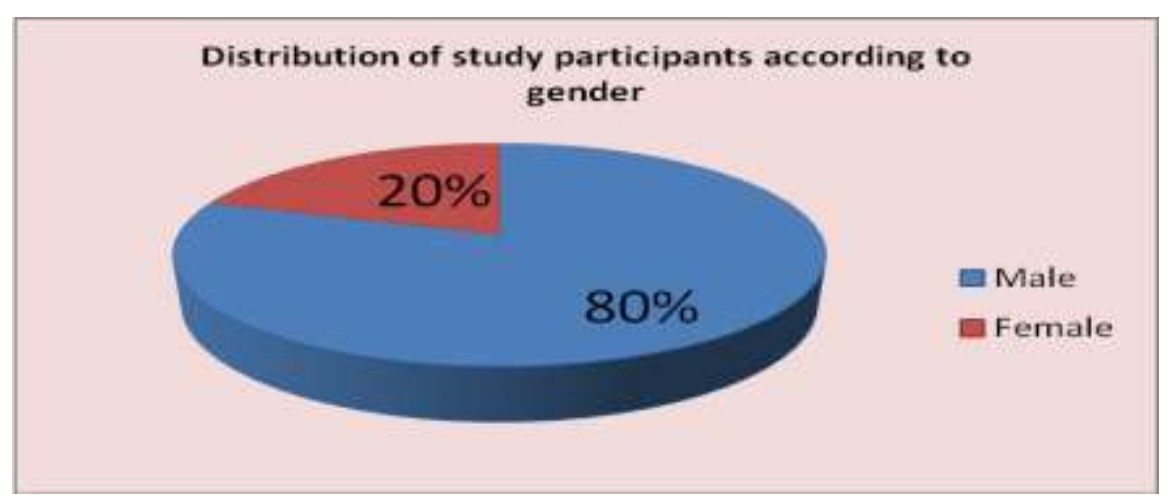

Fig -1: Distribution of study participants according to gender.

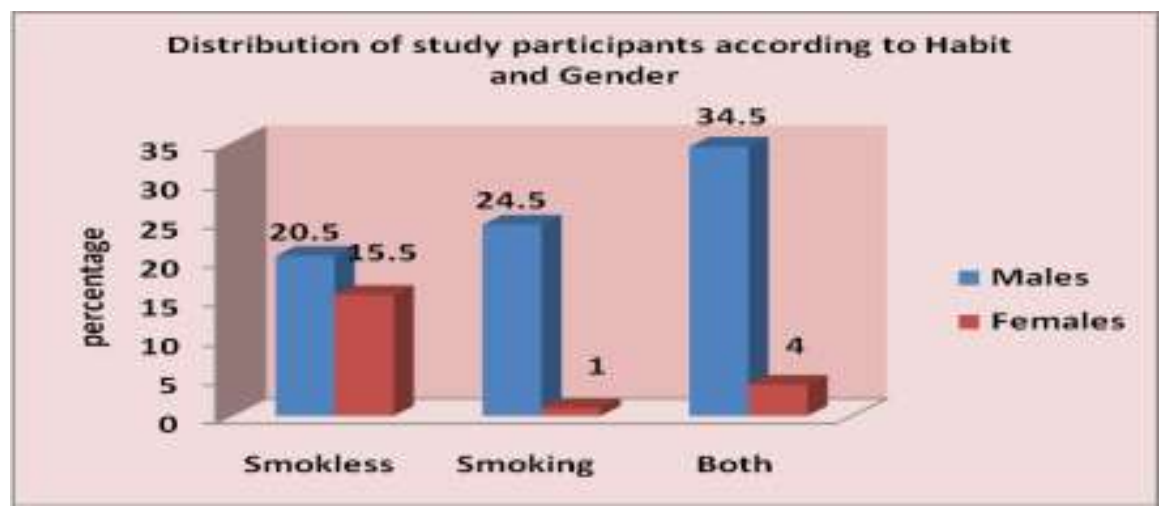

Fig -2: Distribution of study participants according to tobacco habit and gender. 


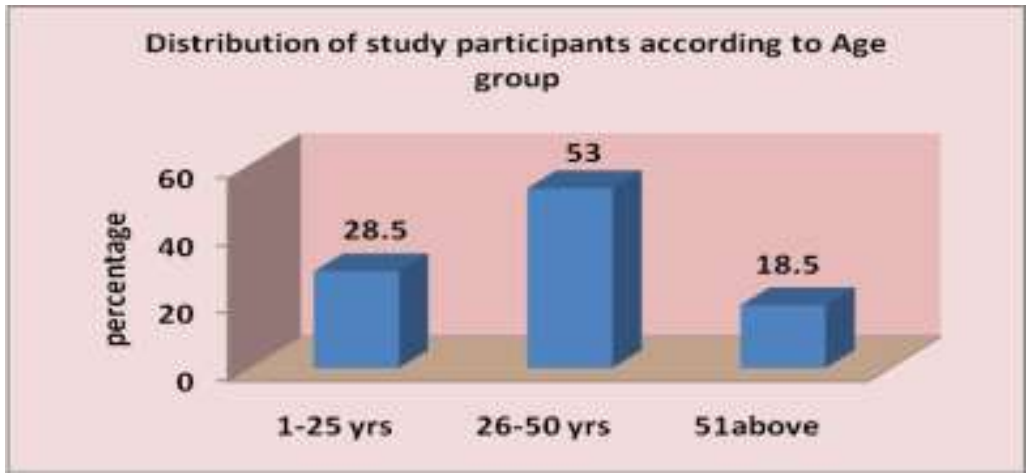

Fig -3:Distribution of study participants according to age group.

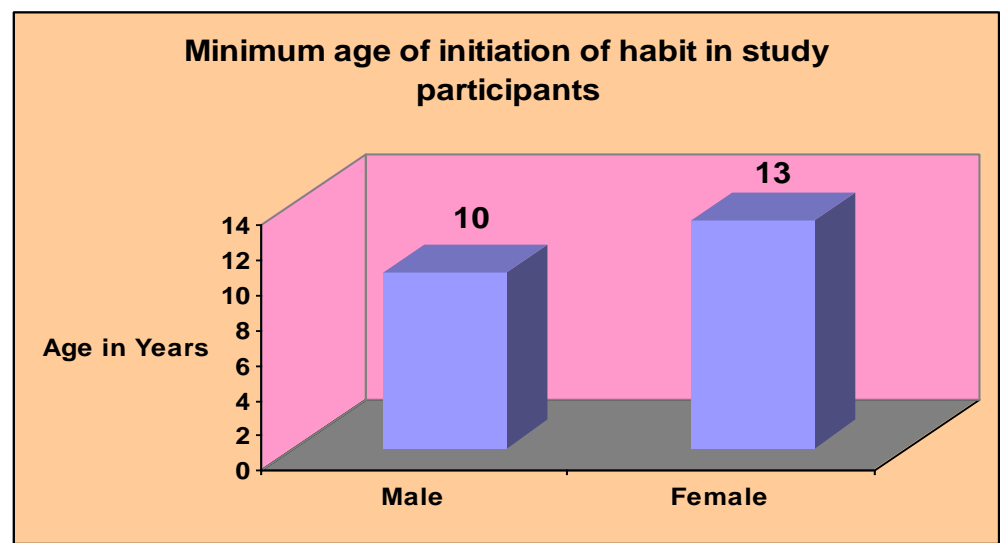

Fig -4: Minimum age of initiation of habit in study participants.

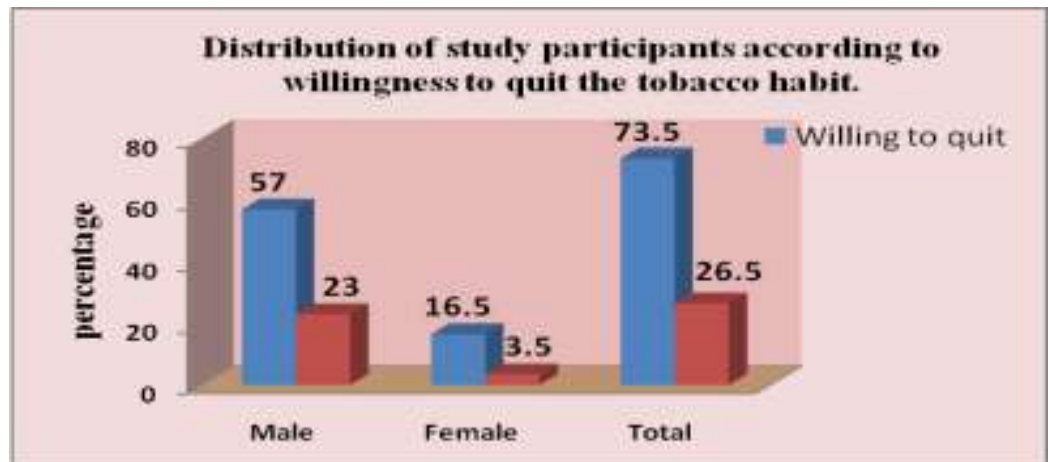

Fig -5: Distribution of study participants according to willingness to quit the tobacco habit.

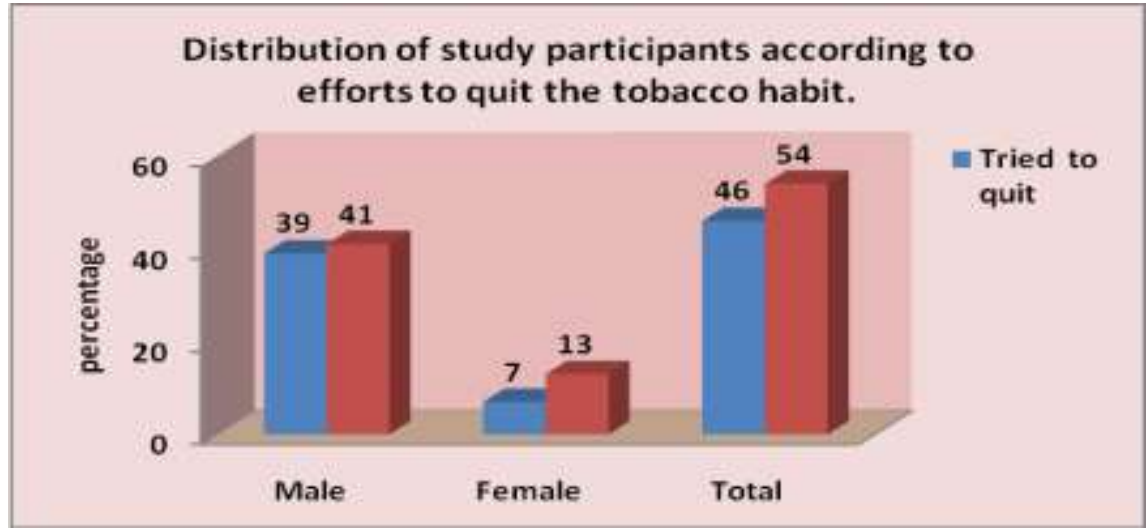

Fig -6: Distribution of study participants according to efforts to quit the tobacco habit. 


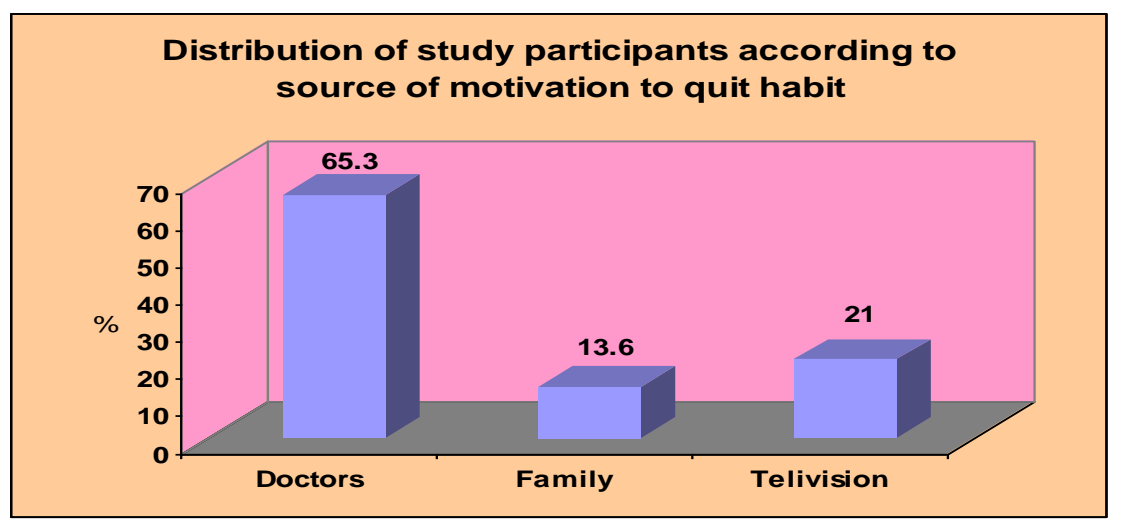

Fig -7: Distribution of study participants according to source of motivation to quit habit.

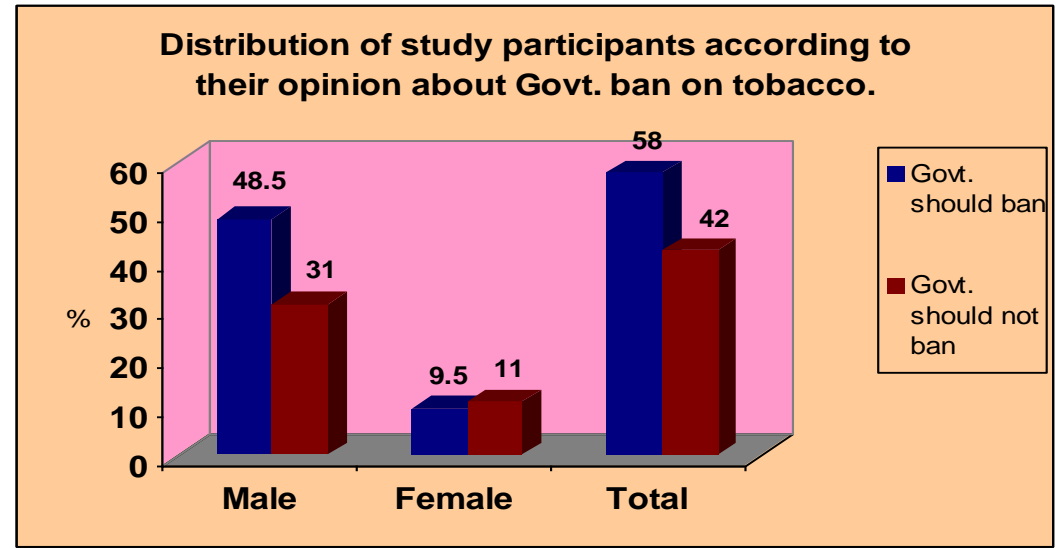

Fig -8: Distribution of study participants according to their opinion about Govt. ban on tobacco.

\section{Conclusion}

There is an urgent need to take effective steps, especially on launching community awareness programs for the school children and public to educate them about the consequences of tobacco use, and on counseling of patients for de-addiction of this habit.

\section{REFERENCES}

[1] Chadda RK, Sengupta SN, Tobacco use by Indian adolescents. Tobacco Induced Diseases Vol. 1, No. 2: 111-119 (2002) , CPTID Society.

[2] Chandrashekhar T Sreeramareddy, PV Kishore, Jagadish Paudel and Ritesh G Menezes, Prevalence and correlates of tobacco use amongst junior collegiates

[3] in twin cities of western Nepal: A cross-sectional, questionnaire-based survey, BioMedCentral Public Health 2008.

[4] GATS India Report 2009-2010, The Global Adult Tobacco Survey (GATS) India, 2009-2010.Ministry of Health and Family Welfare, Government of India, New Delhi.

[5] WHO Library Cataloguing-in-Publication Data, MPOWER: A POLICY PACKAGE TO REVERSE THE TOBACCO EPIDEMIC. c)World Health Organization 2008.

[6] Vinita Singh, Hemraj pal, Manju Mehta and Umesh Kapil, Tobacco consumption and awareness of their health hazards amongst lower income group schoolchildren in national capital territory of Delhi. Indian Pediatrics, volume: 44, 293-294. April 17; 2007.

[7] Urvish Joshi, Bhavesh Modi, Sudha Yadav, A study on prevalence of chewing form of tobacco and existing quitting patterns in urban population of Jamnagar, Gujarat. Indian Journal of Community Medicine Volume: 35, Issue 1,105-108; 2010.

[8] G. Gururaj and N. Girish, Tobacco Use amongst Children in Karnataka. Indian Journal of Pediatrics, Volume 74; 2007.

[9] D N Sinha, P C Gupta, M S Pednekar, Use of tobacco products as dentifrice among adolescents in India: questionnaire study, BMJ VOLUME 328; 2004.

[10] D.N. Sinha Gutka Advertisement and Smokless Tobacco Use by Adolescents in Sikkim, Indian Journal of Community Medicine Vol. 30,2005.

[11] Naresh R. Makwana I, Viral R. Shah II, Sudha Yadav, conducterd A Study on Prevalence of Smoking and Tobacco Chewing among Adolescents in rural areas of Jamnagar District, Gujarat State JMSR • SEPTEMBER 30, 2007;
} 